\title{
The Long-Term Consequences of Maltreatment in the Early Years: A Developmental Pathway Model to Antisocial Behavior
}

\author{
Byron Egeland, Tuppett Yates, \\ Karen Appleyard, and Manfred van Dulmen \\ University of Minnesota \\ Institute of Child Development
}

\begin{abstract}
The developmental pathways linking maltreatment in early childhood and antisocial behavior in adolescence were examined using data from a longitudinal study of high-risk children and their families. Two developmental process variables, emotional/self-regulation (dysregulation) and establishing a close emotional relationship between the child and primary caregiver (alienation), were included in the model in an effort to better understand the pathway from maltreatment to antisocial behavior. The results indicated that alienation and, to a much lesser extent, dysregulation helped explain the relation between early maltreatment and later antisocial behavior. The model including the developmental process variables was a better representation of the data than the model considering only the direct effect between early maltreatment and later antisocial behavior. Physical abuse in early childhood, not emotional neglect, led to alienation in preschool, which then predicted early onset externalizing problems in the elementary school years, ultimately resulting in antisocial behavior in adolescence. One of the implications of these findings for preventing adolescent antisocial behavior is to intervene at an early age with a relationship-based program.
\end{abstract}

Child abuse is a major risk factor for a variety of behavior problems and psychopathology (Bemporad \& Romano, 1992; Luntz \& Widom, 1994). Among the diverse outcomes that have been associated with maltreatment, a strong link has been established between child abuse and antisocial behavior in adolescence

Requests for reprints should be sent to Byron Egeland, Institute of Child Development, 51 East River Road, Minneapolis, MN 55455. E-mail: egela001@umn.edu 
and adulthood (Widom, 1989), particularly for boys (Malinosky-Rummell \& Hansen, 1993). Although the linear relation between child abuse and antisocial behavior is strong, little is known about the developmental process that leads to a pathway of externalizing behavior problems.

We, along with other investigators, have been guided in our study of the sequelae of maltreatment by an organizational perspective of development that focuses on the qualitative reorganization and integration that takes place within and among behavioral and biological systems of the individual (Cicchetti, 1993; Sroufe \& Rutter, 1984). The successful negotiation of stage salient developmental issues at one age (e.g., a secure attachment in infancy) provides a foundation for successful developmental adaptation at a later age (e.g., peer competence in middle childhood). Similarly, experiences such as maltreatment that lead to maladaptation at a particular age (e.g., anxious attachment in infancy) increase the probability of developmental maladaptation at later stages of development (Egeland \& Carlson, in press).

It is well established that abuse occurring in the early years has a negative impact on developmental adaptation as defined by the salient developmental issues of each age (Cicchetti \& Toth, 2000). In infancy, maltreatment is related to insecure and disorganized/disoriented attachments to caregivers (Cicchetti \& Barnett, 1991; Crittenden, 1988; Egeland \& Sroufe, 1981). In the toddler period, maltreated children exhibit disturbances in the development of self/other systems. For example, maltreated toddlers appear to have difficulty talking about the internal states and feelings of self and other (Beeghly \& Cicchetti, 1994). In middle childhood, maltreated children have difficulty with respect to the stage salient issue of peer relationships. For example, Dodge, Pettit, and Bates (1994) found that maltreated children were more disliked by peers, less popular, and more withdrawn in the early school years. Similarly, adolescents with a history of early abuse have been found to interact with their friends in a less intimate fashion compared to nonabused adolescents (Parker \& Herrera, 1996). Using stage salient developmental tasks as indexes of child functioning, these results demonstrate that a major consequence of maltreatment is an impaired ability to achieve expected developmental outcomes across subsequent age periods (i.e., maladaptation). Maladaptation represents a deflection in normal development that may initiate a deviant pathway toward a variety of problems. Thus the effects of maltreatment on stage salient developmental issues and the notion of developmental pathways may help to explain the link between early maltreatment and psychopathology.

In this article we expand on the pathway model to provide a more detailed explanation of the developmental process underlying the relation between maltreatment and antisocial behavior. Specifically, we test the hypothesis that developmental maladaptation in the areas of emotional and behavioral self-regulation, as well as in the development of a close emotional relationship between the child and primary caregiver, contribute to the relation between early maltreatment and 
externalizing behavior in later childhood. Moreover, we explore differences in developmental pathways as a function of the type of maltreatment (physical abuse vs. emotional neglect) experienced in early childhood.

Over the past 2 decades, the construct of self-regulation in young children has become central to many theories of developmental psychopathology (Egeland \& Bosquet, 2002; Sroufe, 1996). Emotional and behavioral self-regulation is a major stage salient issue for the infancy, toddler, and preschool periods. Cicchetti, Ganiban, and Barnett (1991) defined emotion regulation as the factors within an individual and the environment that redirect, control, modulate, and modify emotional arousal to enable an individual to function adaptively in emotionally challenging situations.

It is important to note that regulation is defined in each developmental period. The child moves from dyadic regulation in infancy to caregiver-guided self-regulation in the toddler period and toward independent self-regulation in the preschool period. By the preschool period, the child is expected to regulate his or her own emotional arousal level (and behavioral response to arousal) without the help of a caregiver (Kochanska, 1993). In this investigation, we are interested in the construct of dysregulation in the preschool period. In the preschool period, dysregulation implies that the child has not developed a stable pattern of self-regulation in response to overarousal such that the child will have difficulty regulating behavior and emotions in response to frustration.

Alienation is the second developmental construct hypothesized to underlie or explain the relation between maltreatment and antisocial behavior. Much has been written about the importance of the quality of the developing relationship between the young child and primary caregiver for later development (Maccoby \& Martin, 1983). Alienation refers to the child's avoidance of the primary caregiver and lack of trust in the caregiver's availability, support, and guidance, particularly in stressful situations in which the child needs support and assistance from the caregiver to cope effectively. We predict that maltreatment in early childhood may relate to dysregulation and alienation in preschool, which will then predict externalizing behavior in later childhood.

In addition to the constructs of dysregulation and alienation, our model contains an externalizing behavior latent construct from the middle childhood period. The rationale for this construct is based on the consistent finding that antisocial behavior is one of the most stable behavioral characteristics (Patterson, DeBaryshe, \& Ramsey, 1989). For most adolescents and adults who persist in delinquent and antisocial patterns, disruptive behavior begins early (Robins, 1986) and becomes increasingly stable through the middle childhood years (Achenbach, Howell, Stephanie, McConaughy, \& Stranger, 1995) and adolescence (Egeland, Pianta, \& Ogawa, 1996; Loeber, 1982). Thus it is important to capture the relation between the mediating constructs and early-onset externalizing behaviors in middle childhood. 


\section{MODELS AND METHODS}

Using longitudinal data from infancy through late adolescence, we examined the developmental process by which children who were maltreated at an early age enter a pathway of externalizing behavior that ultimately leads to delinquency and antisocial behavior in adolescence. Using structural equation modeling, we investigated the link between maltreatment in the early years and externalizing behavior in middle childhood, as explained by emotional and behavioral dysregulation and alienation from the primary caregiver in the preschool period.

The sample consisted of 140 high-risk children and their families who had been followed from before birth through age $171 / 2$ and for whom there was no missing data. From this sample, who were part of the Minnesota Longitudinal Study of High-Risk Parents and Children, children were identified as physically abused or emotionally neglected during early childhood (0-54 months). Children classified as physically abused $(n=14)$ were substantiated child protection cases. Children who were emotionally neglected due to psychologically unavailable caregiving $(n$ $=13$ ) were identified by project staff using multiple measures from home and laboratory assessments. As part of the assessment conducted in the home at 3,6 (twice), and 9 months, we observed the mother and baby in feeding and play situations. At 12, 18, 24, and 42 months, we videotaped interactions between mother and child in structured and semistructured laboratory tasks. From these observations we identified a group of mothers who were emotionally distant and unresponsive to the child's bids for comfort and help. These mothers appeared to be detached and uninvolved with their children, interacting with them only when necessary (Egeland \& Erickson, 1987).

The preschool dysregulation latent construct was created to represent the child's self-regulatory pattern and internalized caregiver standards. The variables used to form this latent construct were ratings of the child in the Barrier Box, a laboratory task given at 42 months designed to challenge and frustrate the child in a situation in which the mother was not present (Harrington, Block, \& Block, 1978). In the presence of the experimenter, children were allowed to play with a set of attractive toys that subsequently were removed and placed in a sealed Plexiglas box. Children were faced with the option of trying to open the box to obtain the attractive toys or playing with a set of less attractive toys. Rating scales of ego-control (i.e., the child's ability to cope with frustration, specifically the degree to which the child exercises control over wishes, impulses, and feelings), intensity of help-seeking (i.e., the degree to which the child seeks help from the experimenter), and negative effect were used to construct the dysregulation latent construct.

Variables for the alienation construct were derived from child observation in a teaching task situation that consisted of four challenging child tasks that required parental assistance and teaching strategies. The task, which was also given at 42 months, required children to build blocks from models, name objects with wheels, 
sort objects, and complete a maze. Three 7-point child ratings were selected to represent the child's experience of alienation: avoidance of the mother (i.e., the degree to which the child avoided interacting with the mother), compliance with the mother, and negativity toward the mother. Interrater reliability for both the Barrier Box and teaching task ranged from .79 to .93 .

A latent variable representing externalizing behavior in middle childhood was constructed from teacher ratings on the Child Behavior Checklist (CBCL; Achenbach \& Edelbrock, 1986) administered at the end of Grades 1, 2, and 3. The latent construct reflecting adolescent antisocial behavior problems included two indicators: a composite of parent, teacher, and child report on the CBCL/Youth Self-Report Form (YSRF; Achenbach, 1991a, 1991b; Achenbach \& Edelbrock, 1986) on the subscales delinquent and aggressive behavior at age 16; a diagnosis of conduct disorder obtained from the Schedule of Affective Disorders and Schizophrenia for School-Aged Children (K-SADS; Puig-Antich \& Chambers, 1978) diagnostic interview given at age $171 \frac{1}{2}$.

\section{RESULTS}

The simple correlations and the means and standard deviations are presented in Table 1 . Psychological unavailability was significantly related to the variables making up the alienation construct and to externalizing scores in Grades 1 and 3. Physical abuse was also related to the variables that comprised the alienation construct. In addition, physical abuse was associated with scores on the ego-control variable in the dysregulation construct and higher scores on externalizing in Grades 1,2, and 3. Physical abuse was also significantly related to a diagnosis of conduct disorder at age $171 \frac{1}{2}$.

Additional descriptive statistics are provided in Table 2. The percentage of maltreated children receiving a score of 63 or greater (90th percentile) on the CBCL/YSRF from at least one informant at age 16 was $77 \%$ for the psychologically unavailable group, $79 \%$ for the physically abused group, and $44 \%$ for the nonmaltreated high-risk group. Similarly, $39 \%$ of the psychologically unavailable, $50 \%$ of the physically abused, and $21 \%$ of the nonmaltreated children received a diagnosis of conduct disorder on the K-SADS diagnostic interview given at age $171 / 2$. These results indicate that both psychologically unavailable caregiving and physical abuse in the early years are risk factors for later externalizing behavior problems and conduct disorder in adolescence.

Using LISREL 8.3, we tested two structural equation models: Model 1, in which the relation between physical abuse/psychological unavailability and externalizing problems in middle childhood was partially explained by alienation and dysregulation, and Model 2, in which these same relations were not taken into account. A comparison of the chi-square/df ratio between the two models indi- 
TABLE 1

Descriptive Statistics and Zero-Order Correlations for Indicator Variables

\begin{tabular}{|c|c|c|c|c|c|c|c|c|c|c|c|c|c|c|}
\hline Indicator variable & & 1 & 2 & 3 & 4 & 5 & 6 & 7 & 8 & 9 & 10 & 11 & 12 & 13 \\
\hline $\begin{array}{l}\text { Psychological } \\
\text { unavailability }\end{array}$ & $\begin{array}{l}\text { 1. Psychological } \\
\text { unavailability }\end{array}$ & - & & & & & & & & & & & & \\
\hline Physical abuse & 2. Physical abuse & .22 & - & & & & & & & & & & & \\
\hline \multirow[t]{3}{*}{ Alienation } & 3. Compliance & .16 & .30 & - & & & & & & & & & & \\
\hline & $\begin{array}{l}\text { 4. Avoidance } \\
\text { mother }\end{array}$ & .23 & .20 & .71 & - & & & & & & & & & \\
\hline & $\begin{array}{l}\text { 5. Negativity } \\
\text { toward mother }\end{array}$ & .18 & .21 & .80 & .78 & - & & & & & & & & \\
\hline \multirow[t]{3}{*}{ Dysregulation } & 6. Negative affect & .05 & .10 & .26 & .16 & .18 & - & & & & & & & \\
\hline & $\begin{array}{l}\text { 7. Intensity of help } \\
\text { seeking }\end{array}$ & .07 & .07 & .08 & .05 & .08 & .43 & - & & & & & & \\
\hline & 8. Ego-control & .03 & .19 & .29 & .27 & .27 & .73 & .58 & - & & & & & \\
\hline \multirow[t]{3}{*}{ Externalizing 123} & 9. TRF Grade 1 & .20 & .21 & .09 & .10 & .12 & .07 & .12 & .10 & - & & & & \\
\hline & 10. TRF Grade 2 & .10 & .31 & .22 & .22 & .15 & .23 & .26 & .32 & .58 & - & & & \\
\hline & 11. TRF Grade 3 & .22 & .32 & .30 & .38 & .29 & .24 & .20 & .31 & .52 & .58 & - & & \\
\hline \multirow[t]{4}{*}{$\begin{array}{c}\text { Externalizing } \\
16-171 / 2\end{array}$} & $\begin{array}{l}\text { 12. AGDEL } \\
\text { age } 16\end{array}$ & .14 & .05 & .08 & -.01 & .03 & -.14 & .06 & -.09 & .16 & .11 & .10 & - & \\
\hline & 13. CD age 17 & 11 & .20 & .18 & .11 & .13 & -.01 & .05 & .05 & .27 & .33 & .25 & .29 & - \\
\hline & $M$ & .09 & .10 & 9.34 & 3.76 & 3.99 & 2.32 & 3.67 & 3.36 & 55.94 & 55.61 & 55.18 & $333.96^{\mathrm{a}}$ & .24 \\
\hline & $S D$ & .29 & 30 & 3.20 & 2.65 & 3.01 & 1.38 & 1.55 & 1.41 & 10.93 & 10.44 & 9.61 & 55.24 & .43 \\
\hline
\end{tabular}

Note. $\quad N=140$. Correlations greater than .16 are significant at $p<.05 . \mathrm{TRF}=$ Teacher's Report Form externalizing behavior; AGDEL $=$ aggression/ delinquency; $\mathrm{CD}=$ conduct disorder.

${ }^{a}$ Mean raw score for delinquency and aggression scales from the combined child, parent, and teacher form of the Child Behavior Checklist (Achenbach, 1991a, 1991b; Achenbach \& Edelbrock, 1986). 
TABLE 2

Percentage of Maltreated and Control Children Above the Clinical Range for Externalizing Problems

\begin{tabular}{lcc}
\hline Type of Maltreatment & $\begin{array}{c}\text { \% Above Clinical Cutoff } \\
\text { on CBCL/TRF or } \\
\text { YSRF at Age 16 }\end{array}$ & $\begin{array}{c}\text { \% Diagnosed as Conduct } \\
\text { Disordered on the } \\
\text { K-SADS at 171/2 }\end{array}$ \\
\hline Physical abuse & 64 & 50 \\
Psychological unavailability & 77 & 39 \\
No maltreatment & 38 & 21 \\
\hline
\end{tabular}

Note. Externalizing at age 16 determined by at least one informant with $t$-score above 63 (90th percentile) $. \mathrm{CBCL}=$ Child Behavior Checklist; TRF $=$ Teacher's Report Form; YSRF $=$ Youth Self-Report Form (Achenbach, 1991a, 1991b; Achenbach \& Edelbrock, 1986); K-SADS = Schedule of Affective Disorders and Schizophrenia for School-Aged Children (Puig-Antich \& Chambers, 1978).

cated that Model 1 fit the data better than Model $2\left(\chi^{2} / \mathrm{df}\right.$ change $=26.32(6), \mathrm{p}<$ $.005)$. Model 1, in which the relation between physical abuse/psychological unavailability and externalizing problems was explained by alienation and dysregulation, was a better representation of the data than Model 2, which did not include the mediating relationships.

Overall, Model 1 fit the data well (Root Mean Squared Error of Approximation, RMSEA = .03; Goodness of Fit Index, GFI = .93; see Figure 1). Physical abuse is positively related to alienation $(.19, t=2.24)$, dysregulation $(.22, t=2.07)$, and externalizing problems at Grades 1,2 , and $3(.28, t=3.05)$. However, psychological unavailability was not significantly related to either of the developmental process latent constructs or externalizing in Grades 1,2, and 3. Alienation was a significant predictor of externalizing problems in Grades 1,2 , and $3(.24, t=2.54)$, but dysregulation did not significantly predict externalizing problems in Grades 1, 2, and 3. There was a strong association between externalizing problems at Grades 1, 2 , and 3 and antisocial behavior in adolescence $(.44, t=4.12)$. Model 1 accounted for 26\% of the variance in predicting externalizing problems in Grades 1,2, and 3, and $19 \%$ of the variance in predicting antisocial behavior at age 16-171/2. In comparison, Model 2 (with no mediating relationships) accounted for only $19 \%$ of the variance in predicting externalizing problems at Grades 1,2, and 3 and $21 \%$ of the variance at age 16-171/2 (see Figure 2).

\section{DISCUSSION}

When examined in isolation, physical abuse and psychological unavailability at an early age were found to be risk factors for antisocial behavior in adolescence. This simple relation was demonstrated by the higher percentage of maltreated children compared to nonmaltreated children who were diagnosed as conduct 


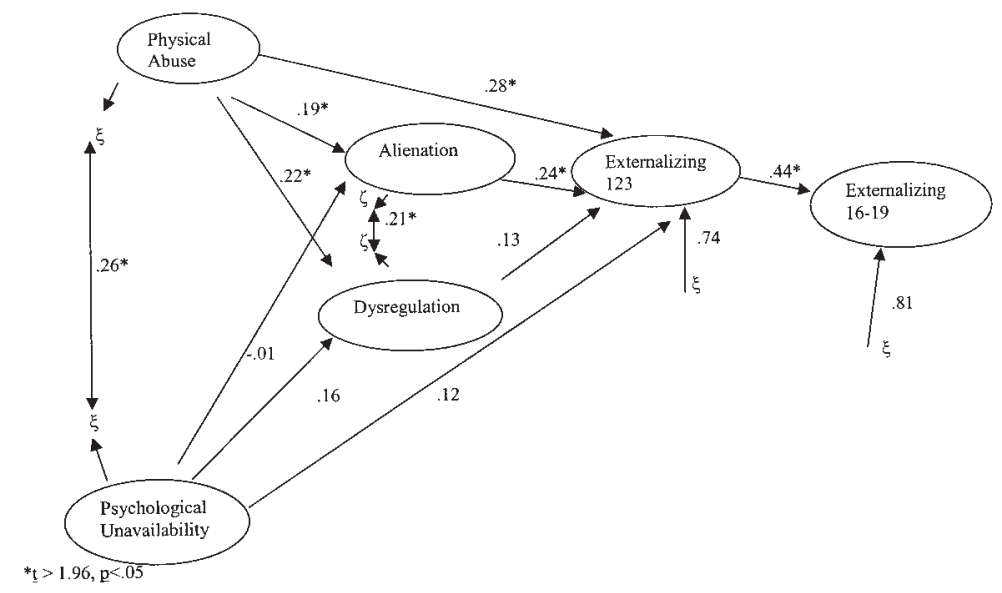

RMSEA $=.030, \mathrm{GFI}=.93, \mathrm{CFI}=.98 \mathrm{CN}=170,47$

FIGURE 1 Overview of Structural Equation Model (Maximum Likelihood Estimation) on Externalizing Problem Behaviors, delinquency/aggression $(N=140$; parameters are completely standardized). RMSEA = Root Mean Squared Error of Approximation; GFI = Goodness of Fit Index; $\mathrm{CFI}=$ Comparative Fit Index; $\mathrm{CN}=$ Critical $N$.

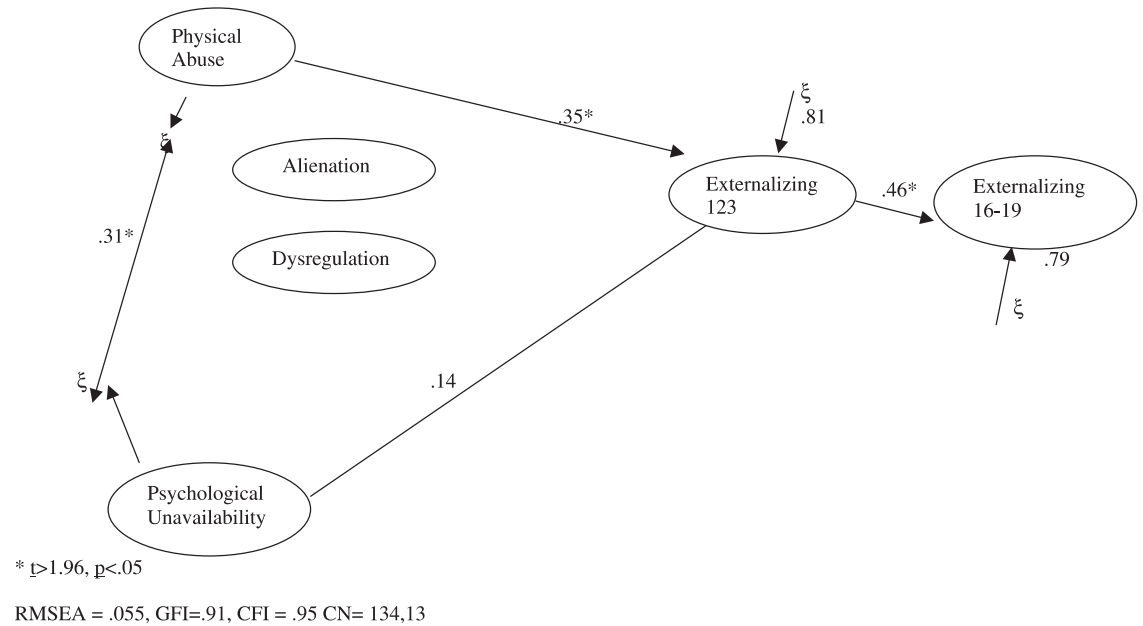

FIGURE 2 Overview of Structural Equation Model (Maximum Likelihood Estimation) on Externalizing Problem Behaviors without mediating relationships, delinquency/aggression $(N$ $=140$; parameters are completely standardized). RMSEA $=$ Root Mean Squared Error of Approximation; GFI $=$ Goodness of Fit Index $; \mathrm{CFI}=$ Comparative Fit Index $; \mathrm{CN}=$ Critical $N$. 
disordered at age $171 \frac{1}{2}$ and who received a score above the 90th percentile on the $\mathrm{CBCL} / \mathrm{YSRF}$ from at least one informant at age 16. However, these relations changed when structural equation modeling procedures were applied to our longitudinal data.

We tested two different models to better understand the simple relation between early maltreatment and antisocial behavior in adolescence. The relation between maltreatment and externalizing behavior problems in Grades 1, 2, and 3 is better explained by including alienation and, to a lesser degree, dysregulation in the model. The inclusion of these developmental process constructs in Model 1 resulted in a significantly better fit of the data than Model 2, which did not include the process constructs. Physical abuse had a significant influence on alienation, and alienation had a significant effect on externalizing behavior in the early elementary school years. Comparing the impact of the two types of maltreatment, psychological unavailability and physical abuse, it is clear that the former had very little effect on the developmental process variables examined here or on early externalizing behavior that led to adolescent antisocial behavior.

The finding that psychologically unavailable caregiving does not directly affect early onset externalizing behavior or the developmental process variables of alienation and dysregulation is somewhat surprising. The simple relation between psychological unavailability and adolescent outcomes (e.g., at age 16, 77\% of the children in this group were above the clinical cutoff on the CBCL) was striking; however, by including physical abuse and the developmental process variables in the structural equation model, psychological unavailability did not make a unique contribution in predicting antisocial behavior. Further research should investigate other possible outcomes of psychological unavailability, such as internalizing problems.

As noted earlier, earlier research showed that abuse has a negative effect on a number of different stage salient developmental issues. In this investigation we examined the influence of maltreatment on two stage salient issues from the preschool period: quality of the parent-child relationship and emotional and behavioral self-regulation. We were also interested in the quality of adaptation on one or both of these stage salient issues as putative mediators of the development of early-onset externalizing behavior problems. A poor quality parent-child relationship, in the form of alienation, was found to be an important mediating variable in the relation between physical abuse and externalizing behavior problems. In sum alienation is a probable consequence of maltreatment that appears to be part of the process leading to an early-onset externalizing trajectory.

These findings offer empirical support for pathways posited by attachment theory from physical abuse to alienation to antisocial behavior and delinquency. Infants who experience harsh caregiving are likely to develop an attachment relationship that is characterized by minimal affective sharing and comfort seeking and a lack of trust in their primary caregiver (Lyons-Ruth \& Jacobvitz, 1999). As 
toddlers and preschoolers, these children have difficulty using their primary caregiver as a secure base to explore their environment and as a source of comfort when distressed (Egeland, Sroufe, \& Erickson, 1983). If this pattern persists into preschool, these children are likely to increasingly distance themselves from the caregiver. Over time alienation becomes a stable characteristic of these children, which may lead to antisocial behavior.

The failure to find a significant pathway from dysregulation to externalizing behavior in Grades 1, 2, and 3 is somewhat surprising. It may be that the variables from the Barrier Box observation used to construct the dysregulation latent construct were not a valid measure of emotional and behavioral self-regulation. For example, it is possible that not all children were frustrated by the task; therefore, the task did not tap the child's resources to cope with high levels of arousal. Alternatively, because the mother was not present for the Barrier Box task, it is possible that the child's coping strategy was not the same as it would have been in the presence of the mother. Perhaps a better test of regulation for children who are 42 months old would be a task in which the mother is present. It should also be noted that the association between dysregulation and externalizing is influenced by controlling for the relation among the earlier variables (i.e., types of maltreatment). Changing control variables (e.g., eliminating physical abuse) in the structural equation model would likely change the association between dysregulation and externalizing.

The current data yield important implications for prevention and intervention efforts. First, because physical abuse and psychological unavailability appear to have unique developmental pathways and possibly outcomes, treatment for families with different maltreatment histories will vary. Thus efforts to prevent delinquency should be tailored to the specific developmental and relationship history of the child. Alienation appears to be an important developmental process variable that explains the relation between physical abuse and later antisocial behavior. Thus these data suggest that intervention efforts aimed at preventing later antisocial and delinquent behavior among maltreated youth may be most profitably directed toward interventions that foster a sense of connectedness and reciprocity between the child and caregiver. Prevention programs designed to promote a secure parent-infant attachment relationship have been found to be reasonably successful (Egeland, Weinfield, Bosquet, \& Cheng, 2000). However, similar programs for preschool and older children and their primary caregivers still need to be developed. Intervention programs designed to enhance the quality of the parent-child relationship would likely reduce alienation between child and caregiver and ultimately prevent future behavior problems. In addition to the need to develop relationship-based interventions, policymakers need to be aware that other factors may influence the quality of the developing relationship between the parent and young child, such as adequate family housing, medical care, medical leave, and availability of day care. 


\section{ACKNOWLEDGMENTS}

Preparation of this work and the research described herein was supported by a grant from the National Institute of Mental Health (MH 40864-16). This article was presented at the Annual Meeting of the American Psychological Association, San Francisco, August 26, 2001.

\section{REFERENCES}

Achenbach, T. M. (1991a). Manual for Child Behavior Checklist 4-18 and 1991 profile. Burlington, VT: University of Vermont Department of Psychiatry.

Achenbach, T. M. (1991b). Manual for Youth Self Report 4-18 and 1991 profile. Burlington, VT: University of Vermont Department of Psychiatry.

Achenbach, T. M., \& Edelbrock, C. (1986). Manual for the Teacher's Report Form and teacher version of the child behavior profile. Burlington, VT: University of Vermont Department of Psychiatry.

Achenbach, T. M., Howell, C. T., Stephanie, M. S., McConaughy, H., \& Stranger, C. (1995). Six-year predictors of problems in a national sample of children and youth: Cross informant syndromes. Journal of the American Academy of Child and Adolescent Psychiatry, 34, 336-347.

Beeghly, M., \& Cicchetti, D. (1994). Child maltreatment, attachment, and the self system: Emergence of an internal state lexicon in toddlers at high social risk. Development and Psychopathology, 6, 5-30.

Bemporad, J. R., \& Romano, S. J. (1992). Childhood maltreatment and adult depression: A review of research. In D. Cicchetti \& S. L. Toth (Eds.), Rochester Symposium on Developmental Psychopathology: Vol. 4. Developmental perspectives on depression (pp. 351-376). Rochester, NY: University of Rochester Press.

Cicchetti, D. (1993). Developmental psychopathology: Reactions, reflections, projections. Developmental Review, 13, 471-502.

Cicchetti, D., \& Barnett, D. (1991). Attachment organization in preschool aged maltreated children. Development and Psychopathology, 3, 397-411.

Cicchetti, D., Ganiban, J., \& Barnett, D. (1991). Contributions from the study of high-risk populations to understanding the development of emotion regulation. In J. Garber \& K. Dodge (Eds.), The development of emotion regulation and dysregulation (pp. 15-48). New York: Cambridge University Press.

Cicchetti, D., \& Toth, S. L. (2000). Developmental processes in maltreated children. In D. Hansen (Ed.), Nebraska Symposium on Motivation, Vol. 46: Child maltreatment. Lincoln: University of Nebraska Press.

Crittenden, P. M. (1988). Relationships at risk. In J. Belsky \& T. Nezworski (Eds.), Clinical implications of attachment theory (pp. 136-174). Hillsdale, NJ: Lawrence Erlbaum Associates, Inc.

Dodge, K. A., Pettit, G. S., \& Bates, J. E. (1994). Effects of physical maltreatment on the development of peer relations. Development and Psychopathology, 6, 43-55.

Egeland, B., \& Bosquet, M. (2002). Emotion regulation in early childhood: The role of attachment-oriented interventions. In B. S. Zuckerman, A. F. Lieberman, \& N. A. Fox (Eds.), Socioemotional regulation: Dimensions, developmental trends, and influences (pp. 101-124). Skillman, NJ: Johnson \& Johnson Pediatric Institute.

Egeland, B., \& Carlson, E. (in press). Attachment and psychopathology. In L. Atkinson (Ed.), Clinical applications of attachment. Mahwah, NJ: Lawrence Erlbaum Associates, Inc. 
Egeland, B., \& Erickson, M. F. (1987). Psychologically unavailable caregiving: The effects on development of young children and the implications for intervention. In M. Brassard, B. Germain, \& S. Hart (Eds.), Psychological maltreatment of children and youth (pp. 110-120). New York: Pergamon.

Egeland, B., Pianta, R., \& Ogawa, J. (1996). Early behavior problems: Pathways to mental disorders in adolescence. Development and Psychopathology, 8, 735-749.

Egeland, B., \& Sroufe, L. A. (1981). Developmental sequelae of maltreatment in infancy. In R. Rizley and D. Cicchetti (Eds.), New directions for child development: Developmental perspectives in child maltreatment (pp. 77-92). San Francisco: Jossey-Bass.

Egeland, B., Sroufe, L. A., \& Erickson, M. F. (1983). Developmental consequences of different patterns of maltreatment. Child Abuse and Neglect, 7, 459-469.

Egeland, B., Weinfield, N. S., Bosquet, M., \& Cheng, V. K. (2000). Remembering, repeating, and working through: Lessons from attachment-based interventions. In J. D. Osofsky \& H. E. Fitzgerald (Eds.), Infant Mental Health in Groups at High Risk. WAIMH Handbook of infant mental health, Vol. 4 (pp. 35-89). New York: Wiley.

Harrington, D. M., Block, J. H., \& Block, J. (1978). Intolerance of ambiguity in preschool children: Psychometric considerations, behavioral manifestations, and parental correlates. Developmental Psychology, 14, 242-245.

Kochanska, G. (1993). Toward a synthesis of parental socialization and child temperament in early development of conscience. Child Development, 64, 325-347.

Loeber, R. (1982). The stability of antisocial and delinquent child behavior: A review. Child Development, 53, 1431-1446.

Luntz, B., \& Widom, C. (1994). Antisocial personality disorder and abused and neglected children grown up. American Journal of Psychiatry, 151, 670-674.

Lyons-Ruth, K., \& Jacobvitz, D. (1999). Attachment disorganization: Unresolved loss, relational violence, and lapses in behavioral and attentional strategies. In J. Cassidy \& P. R. Shaver (Eds.), Handbook of attachment: Theory, research, and clinical applications (pp. 520-554). New York: Guilford.

Maccoby, E., \& Martin, J. A. (1983). Socialization in the context of the family: Parent-child interaction. In P. H. Mussen (Series Ed.), \& E. M. Hetherington (Vol. Ed.), Handbook of child psychology: Vol.4. Socialization, personality, and social development (4th ed., pp.1-102). New York: Wiley.

Malinosky-Rummell, R., \& Hansen, D. (1993). Long-term consequences of childhood physical abuse. Psychological Bulletin, 114, 68-79.

Parker, J. G., \& Herrera, C. (1996). Interpersonal processes in friendship: A comparison of maltreated and non-maltreated children's experiences. Developmental Psychology, 32, 1025-1038.

Patterson, G. R., DeBaryshe, B. D., \& Ramsey, E. (1989). A developmental perspective on antisocial behavior. American Psychologist, 44(2), 329-335.

Puig-Antich, J., \& Chambers, W. (1978). The schedule of affective disorders and schizophrenia for school-aged children. New York: New York Psychiatric Institute.

Robins, L. N. (1986). Deviant children grown-up: A sociological and psychiatric study of sociopathic personality. Baltimore: Williams \& Wilkins.

Sroufe, L. A. (1996). Emotional development: The organization of emotional life in the early years. New York: Cambridge University Press.

Sroufe, L. A., \& Rutter, M. (1984). The domain of developmental psychopathology. Child Development, 55, 17-29.

Widom, C. S. (1989). Child abuse, neglect, and violent criminal behavior. Criminology, 2, 251-271. 
Copyright of Children's Services: Social Policy, Research \& Practice is the property of Lawrence Erlbaum Associates and its content may not be copied or emailed to multiple sites or posted to a listserv without the copyright holder's express written permission. However, users may print, download, or email articles for individual use. 